\title{
Studies on Variability, Heritability and Genetic Advance for Yield and its Related Traits in Rice (Oryza sativa L) Genotypes
}

\author{
Ally Mwichande Russinga ${ }^{1,3^{*}}$, A. Srividhya ${ }^{2}$, V. L. N. Reddy ${ }^{1}$ and P. Latha $^{2}$ \\ ${ }^{1}$ Department of Genetics and Plant Breeding, S.V. Agricultural College, AGRAU, India \\ ${ }^{2}$ Regional Agricultural Research Station, Tirupati, India \\ ${ }^{3}$ Tanzania Agricultural Research Institute (TARI), Ifakara Center, Ifakara, Tanzania \\ *Corresponding author
}

\section{A B S T R A C T}

Ke y w o r d s
Rice (Oryza sativa
L.), Genetic
variability,
Heritability,
Genetic advance
Article Info
Accepted:
20 August 2020
Available Online:
10 September 2020

\section{Keywords}

Rice (Oryza sativa

L.), Genetic

variability,

Heritability,

Article Info

Accepted:

10 September 2020

\begin{abstract}
The panel comprises of landraces, improved varieties, interspecific derivatives (Oryza glaberrimax Oryza sativa), aromatic and japonica rice etc. were evaluated during Kharif 2019 used for studying genetic variability, heritability and genetic advance for yield and its related traits in rice. The analysis of variance of 12 different characters of 30 rice genotypes showed differences among the genotypes which revealed that there was genetic variation among the genotypes studied. Phenotypic coefficient of variance was found higher than genotypic coefficient of variance for all studied traits indicate the environmental influence on the expression of these traits. Among the studied traits broad sense heritability ranged from $47.00 \%$ (productive tillers) to $94.50 \%$ (grain width). The characters plant height, filled grains, total grains, grain length, grain width and grain ratio have high genetic advance as per cent of mean along with high heritability. High heritability with high genetic advance as per cent of mean indicates that these characters are largely controlled by additive gene action would be effective for selecting superior varieties.
\end{abstract}

\section{Introduction}

Rice (Oryza sativa L.) is an important crop, which supplies staple food for more than fifty percent of the global population. Among the most cultivated cereals in the world, rice ranks as second to wheat (i.e. 161.62 million hectares) (USDA, 2020). Over 90 percent of the world's rice is produced and consumed in the Asian Region by six countries (China, India, Indonesia, Bangladesh, Vietnam and Japan) comprising $80 \%$ of the world's production and consumption (USDA, 2020).The genus, Oryza consists of mainly two cultivated species and 22 wild species. The cultivated species, Oryza sativa $(2 \mathrm{n}=24$ AA) is grown worldwide while Oryza glaberrima $(2 \mathrm{n}=24$ AA) is planted on a limited scale in West Africa.

The primary consideration to bring about genetic improvement of crop is the study of genetic variability. Assessment of genetic variability of any trait is pre-requisite for a 
plant breeder to planning effective breeding programmes. Heritability is an index of the transmission of characters from parents to their offspring and it plays an important role in plant breeding. Genetic advance provides information on expected gain resulting from selection of superior individuals (Lingaiah, 2015). Heritability estimates along with genetic advance is more precise in predicting the genetic gain under selection than heritability alone (Adhikari et al., 2018). The present study was undertaken to determine the extent variability, heritability and genetic advance for yield and its contributing traits in rice genotypes.

\section{Materials and Methods}

In the present study, a core set of 30 rice genotypes were chosen based on their yield component trait diversity under different subgroups (japonica, indica and aromatic) from around 250 genotypes available at the Department of Genetics and Pant Breeding, S.V. Agricultural College, Tirupati. The panel comprises of landraces, improved varieties, interspecific derivatives (Oryza glaberrimax Oryza sativa), aromatic and japonica rice etc were used for correlation analysis of yield contributing traits (Table 1).

The experiment was carried out at Wetland Farm, S.V. Agricultural College, Tirupati, ANGRAU during Kharif, 2019. The experiment was laid out in three replications in Randomized Block Design (RBD) with spacing of $20 \mathrm{~cm} \times 15 \mathrm{~cm}$ and 2 rows of $4 \mathrm{~m}$ length. The agronomic management was done as per the standard recommendations. The phenotypic data was recorded for the twelve yield contributing traits from 5 plants per replication per genotype. The productive tillers (PT), plant height $(\mathrm{PH})$, panicle length (PL), filled grains (FG), chaffy grains (CG), number of total grains $(\mathrm{GN})$, percentage of spikelet fertility (SF), grain length (GL), grain width (GW), grain ratio (GR),1000-grain weight (TGW) and grain yield per plant (GY), were evaluated. For each trait, means of the replicates were used in the data analyses (Table 2). The data was subjected to INDOSTAST 9.2 software to estimate genetic co-efficient of variation (\%) (GCV), phenotypic co-efficient of variation (\%) (PCV), heritability (\%) (broad sense), genetic advance and genetic advance as per cent of mean. The estimates for variability treated as per the categorization proposed by Sivasubramanian and Madhavamenon (1973) i.e., low: less than 10 per cent, moderate: 1020 per cent and high: more than 20 per cent. Heritability (Low: less than 30\%, moderate: $30-60 \%$ and high: more than 60\%) and genetic advance as mean per cent of mean estimates (Low: less than 10\%, moderate: 10 $20 \%$ and high: more than $20 \%$ according to criteria proposed by Johnson et al., (1955).

\section{Results and Discussion}

The analysis of variance of 12 different characters of 30 rice genotypes showed differences among the genotypes which revealed that there was genetic variation among the genotypes studied (Table 3). This is in agreement with works of (Shahriar et al., 2014; Singh et al., 2014). This suggested the selection of superior and diverse genotypes for use in escalating the genetic yield potential of rice. Mean, along with the variability estimates such as the phenotypic coefficient of variation (PCV), the genotypic coefficient of variation (GCV), broad sense heritability, and genetic advance as percent of means are presented in Table 4. Phenotypic coefficient of variance was found higher than genotypic coefficient of variance for all studied traits indicate the environmental influence on the expression of these traits (Table 4). Similar results were presented by Rashid et al., 2017; Gyawali et al., 2018. The extent of the influence of growing 
environment on observed traits is explained by the magnitude of the differences between GCV and PCV. Large difference between PCV and GCV indicate high environmental influence on the expression of particular traits. In the present study, phenotypic coefficient of variation in general were higher than genotypic coefficient of variation for all the traits indicating high environmental effect on the expression of these traits except grain length (PCV 10.97\%, GCV 10.38\%) and grain width(PCV $14.41 \%$, GCV $14.01 \%$ ) which were less affected by environment for expression (Table 4). Thus, selection based on phenotypic performance for grain length and grain width would be effective to bring about considerable genetic improvement.

Table.1 List of rice genotypes used in the present study

\begin{tabular}{|c|c|c|}
\hline S.No. & Genotype & Subspecies/Group \\
\hline 1 & Abhaya & Indica \\
\hline 2 & Aditya & Indica \\
\hline 3 & AMO & Indica \\
\hline 4 & Anjali & Indica \\
\hline 5 & Azucena & Aromatic, Japonica \\
\hline 6 & Badshabhog & Indica \\
\hline 7 & Burma Black & Indica/Landrace \\
\hline 8 & Daddiga & Indica \\
\hline 9 & Disang & Indica \\
\hline 10 & Haryana Basmati & Aromatic, Indica \\
\hline 11 & HIM 799 & Indica \\
\hline 12 & Kesari & Indica \\
\hline 13 & Krishna & Indica \\
\hline 14 & Luit & Indica \\
\hline 15 & Mrunalini & Indica \\
\hline 16 & NL 1 (Nerica line 1) & Og/os \\
\hline 17 & NL 16 (Nerica line 16) & Og/os \\
\hline 18 & NL 3 (Nerica line 3) & Og/os \\
\hline 19 & NL 9 (Nerica line 9) & Og/os \\
\hline 20 & Numali & Indica \\
\hline 21 & Pant Sugandh Dhan 15 & Aromatic, Indica \\
\hline 22 & Pathariya & Indica \\
\hline 23 & RPBio 248 & Indica/Indica wild \\
\hline 24 & SannaJajula & Indica \\
\hline 25 & Savithri & Indica \\
\hline 26 & Sharbati & Indica \\
\hline 27 & Solumpiket & Indica \\
\hline 28 & Taramati & Aromatic, Indica \\
\hline 29 & TKM 6 & Indica \\
\hline 30 & WAB450-24-32-P18-HB & Og/os \\
\hline
\end{tabular}


Table.2 Agronomic performance of rice genotypes

\begin{tabular}{|c|c|c|c|c|c|c|c|c|c|c|c|c|c|}
\hline S.No. & Genotype & PT & PL(cm) & $\mathbf{P H}(\mathrm{cm})$ & FG & CG & GN & SF $(\%)$ & GL & GW & GR & TGW(g) & $\mathbf{Y P}(\mathbf{g})$ \\
\hline 1 & Abhaya & 10.60 & 25.27 & 120.80 & 123.43 & 16.38 & 139.82 & 89.00 & 8.71 & 2.41 & 3.61 & 22.58 & 22.18 \\
\hline 2 & Aditya & 10.60 & 21.93 & 81.20 & 58.58 & 11.60 & 70.18 & 84.00 & 8.81 & 2.77 & 3.18 & 24.69 & 7.90 \\
\hline 3 & AMO & 11.58 & 24.07 & 101.60 & 158.73 & 34.00 & 192.73 & 83.00 & 8.16 & 2.55 & 3.21 & 21.40 & 25.49 \\
\hline 4 & Anjali & 6.80 & 26.33 & 113.60 & 78.53 & 12.67 & 91.20 & 86.00 & 8.03 & 3.02 & 2.66 & 24.34 & 8.48 \\
\hline 5 & Azucena & 15.00 & 26.13 & 98.42 & 125.58 & 23.92 & 149.50 & 84.00 & 10.41 & 2.91 & 3.57 & 27.71 & 29.47 \\
\hline 6 & Badshabhog & 10.33 & 28.73 & 118.87 & 147.27 & 29.87 & 177.13 & 83.00 & 10.03 & 2.41 & 4.16 & 21.74 & 21.42 \\
\hline 7 & Burma Black & 7.02 & 28.33 & 175.33 & 190.47 & 18.33 & 208.80 & 91.00 & 9.57 & 3.49 & 2.74 & 28.71 & 28.14 \\
\hline 8 & Daddiga & 7.20 & 23.60 & 128.73 & 180.17 & 21.67 & 201.83 & 89.00 & 7.36 & 3.31 & 2.22 & 24.65 & 19.03 \\
\hline 9 & Disang & 11.47 & 23.93 & 95.80 & 86.85 & 15.88 & 102.73 & 85.00 & 8.09 & 2.58 & 3.14 & 24.43 & 10.22 \\
\hline 10 & Haryana Basmati & 8.93 & 22.07 & 87.87 & 137.60 & 29.87 & 167.47 & 82.00 & 8.48 & 2.17 & 3.91 & 15.00 & 16.64 \\
\hline 11 & HIM799 & 15.00 & 25.87 & 106.60 & 103.00 & 41.00 & 144.00 & 72.00 & 9.00 & 2.55 & 3.54 & 30.03 & 19.68 \\
\hline 12 & Kesari & 15.53 & 21.13 & 97.60 & 148.80 & 16.67 & 165.47 & 90.00 & 8.14 & 2.53 & 3.22 & 18.54 & 29.93 \\
\hline 13 & Krishna & 8.13 & 24.20 & 101.40 & 175.27 & 51.07 & 226.33 & 78.00 & 8.57 & 2.16 & 3.98 & 15.94 & 20.08 \\
\hline 14 & Luit & 7.67 & 23.13 & 95.13 & 106.87 & 25.87 & 132.73 & 80.00 & 9.14 & 2.59 & 3.53 & 22.27 & 11.03 \\
\hline 15 & Mrunalini & 10.87 & 28.73 & 130.47 & 189.49 & 49.89 & 239.37 & 79.00 & 9.44 & 2.39 & 3.95 & 22.57 & 32.71 \\
\hline 16 & NL1 & 10.67 & 22.87 & 82.47 & 78.87 & 34.87 & 113.73 & 69.00 & 9.80 & 2.45 & 3.99 & 22.78 & 13.59 \\
\hline 17 & NL16 & 9.87 & 25.67 & 109.20 & 101.55 & 28.80 & 130.35 & 78.00 & 9.75 & 2.52 & 3.87 & 26.21 & 19.91 \\
\hline 18 & NL3 & 10.53 & 26.13 & 92.67 & 89.25 & 29.50 & 118.75 & 76.00 & 10.36 & 2.68 & 3.87 & 25.35 & 10.74 \\
\hline 19 & NL9 & 11.00 & 26.07 & 82.33 & 75.00 & 27.00 & 102.20 & 74.00 & 10.11 & 2.52 & 4.01 & 26.15 & 14.27 \\
\hline 20 & Numali & 7.00 & 24.33 & 129.60 & 221.63 & 30.58 & 252.22 & 88.00 & 8.14 & 2.81 & 2.90 & 21.23 & 22.39 \\
\hline 21 & Pant Sugandh 15 & 11.58 & 29.20 & 99.93 & 95.82 & 48.97 & 144.78 & 66.00 & 10.46 & 2.27 & 4.61 & 21.01 & 16.88 \\
\hline 22 & Pathariya & 21.60 & 24.07 & 126.00 & 75.22 & 7.11 & 82.33 & 92.00 & 8.41 & 3.18 & 2.65 & 24.45 & 17.32 \\
\hline 23 & RPBio/248 & 12.11 & 27.53 & 117.27 & 128.27 & 23.93 & 152.20 & 84.00 & 8.29 & 2.79 & 2.97 & 26.77 & 25.01 \\
\hline 24 & Sanna Jajula & 9.53 & 32.33 & 157.73 & 170.77 & 38.30 & 209.07 & 81.00 & 11.49 & 1.77 & 6.51 & 17.86 & 22.82 \\
\hline 25 & Savitri & 7.13 & 22.93 & 93.73 & 140.17 & 42.28 & 182.44 & 77.00 & 9.16 & 2.66 & 3.45 & 23.22 & 21.63 \\
\hline 26 & Sharbati & 13.16 & 25.60 & 109.27 & 126.10 & 25.75 & 151.85 & 83.00 & 9.69 & 2.11 & 4.72 & 20.40 & 18.78 \\
\hline 27 & Solumpiket & 9.84 & 26.00 & 102.20 & 84.25 & 25.30 & 109.55 & 80.00 & 9.30 & 2.50 & 3.78 & 23.99 & 16.01 \\
\hline 28 & Taramati & 9.53 & 22.00 & 100.87 & 170.27 & 59.67 & 229.93 & 74.00 & 7.71 & 2.29 & 3.37 & 16.08 & 13.11 \\
\hline 29 & TKM6 & 10.13 & 25.07 & 82.40 & 114.87 & 76.13 & 191.00 & 60.00 & 9.93 & 2.22 & 4.47 & 17.95 & 12.86 \\
\hline \multirow[t]{6}{*}{30} & WAB-450 & 9.00 & 25.20 & 101.00 & 104.80 & 56.60 & 161.40 & 66.00 & 8.97 & 2.64 & 3.39 & 20.43 & 12.11 \\
\hline & Mean & 10.65 & 25.28 & 108.00 & 126.25 & 31.78 & 158.04 & 80.00 & 9.12 & 2.57 & 3.64 & 22.62 & 18.66 \\
\hline & Lowest range & 21.60 & 32.33 & 175.33 & 221.63 & 76.13 & 252.22 & 91.00 & 11.49 & 3.49 & 6.50 & 30.03 & 32.72 \\
\hline & Highest range & 6.80 & 21.13 & 81.20 & 58.58 & 7.11 & 70.18 & 60.00 & 7.36 & 1.77 & 2.22 & 15.00 & 7.90 \\
\hline & C.V. & 26.57 & 5.79 & 6.34 & 15.76 & 37.95 & 15.58 & 7.99 & 3.54 & 3.38 & 7.95 & 14.18 & 28.02 \\
\hline & ANOVA $P$-value & $0.00 * *$ & $0.00 * *$ & $0.00 * *$ & $0.00 * *$ & $0.00 * *$ & $0.00 * *$ & $0.00 * *$ & $0.00 * *$ & $0.00 * *$ & $0.00 * *$ & $0.00 * *$ & $0.00 * *$ \\
\hline
\end{tabular}


Table.3 Analysis of Variance (ANOVA) for yield and contributing traits

\begin{tabular}{|l|l|c|c|c|c|c|}
\hline S.No & Trait & Replication & Treatment & Error & F ratio & P value \\
\hline $\mathbf{1}$ & PT & 39.39632 & 29.29591 & 8.00406 & 3.6601 & $0.000^{* *}$ \\
\hline $\mathbf{2}$ & PL(cm) & 3.612 & 18.81945 & 2.143035 & 8.7817 & $0.000^{* *}$ \\
\hline $\mathbf{3}$ & PH(cm) & 0.728007 & 1392.645 & 46.8082 & 29.7522 & $0.000^{* *}$ \\
\hline $\mathbf{4}$ & FG & 201.3338 & 5260.321 & 395.7462 & 13.2922 & $0.000 * *$ \\
\hline $\mathbf{5}$ & CG & 73.17824 & 752.1923 & 145.615 & 5.1656 & $0.000 * *$ \\
\hline $\mathbf{6}$ & GN & 56.29593 & 7037.815 & 606.5634 & 11.6028 & $0.000^{* *}$ \\
\hline $\mathbf{7}$ & SF(\%) & 0.7054 & 1.8652 & 0.4094 & 4.5565 & $0.000^{* *}$ \\
\hline $\mathbf{8}$ & GL(mm) & 0.036743 & 2.791779 & 0.104347 & 26.7548 & $0.000 * *$ \\
\hline $\mathbf{9}$ & GW $(\mathrm{mm})$ & 0.000724 & 0.39802 & 0.007573 & 52.5597 & $0.000^{* *}$ \\
\hline $\mathbf{1 0}$ & GR & 0.00772 & 1.940174 & 0.083727 & 23.1727 & $0.000 * *$ \\
\hline $\mathbf{1 1}$ & TGW $(\mathrm{g})$ & 20.0928 & 42.55748 & 10.28684 & 4.1371 & $0.000 * *$ \\
\hline $\mathbf{1 2}$ & YP $(\mathrm{g})$ & 25.9534 & 130.6254 & 27.34488 & 4.777 & $0.000^{* *}$ \\
\hline
\end{tabular}

PT, Number of productive per plant; PL, Panicle length; PH, Plant height; FG, Number of filled grains per panicle; CG, Number of chaffy grains per panicle; GN,Total grains number per panicle; GL, Grain length (mm); GW, Grain width (mm); GL/GW, Grain length to width ratio; TGW,1000-grain weight; YP, Yield per plant

Table.4 Mean, phenotypic (Vp) and genotypic variance (Vg), phenotypic coefficient (PCV) and genotypic coefficient of variance (GCV), heritability (broad sense), genetic advance (GA) and genetic advance as percent of mean (GAM) for observed traits

\begin{tabular}{|r|l|c|c|c|c|c|c|c|c|}
\hline S.No & Trait & Mean & Vg & Vp & Hbs(\%) & GCV(\%) & PCV(\%) & GA & GAM(\%) \\
\hline $\mathbf{1}$ & PT & 10.65 & 7.10 & 15.10 & 47.00 & 25.02 & 36.50 & 3.76 & 35.34 \\
\hline $\mathbf{2}$ & PL(cm) & 25.28 & 5.56 & 7.70 & 72.20 & 9.32 & 10.98 & 4.13 & 16.32 \\
\hline $\mathbf{3}$ & PH(cm) & 108.00 & 448.61 & 495.42 & 90.60 & 19.61 & 20.61 & 41.52 & 38.44 \\
\hline $\mathbf{4}$ & FG & 126.25 & 1621.53 & 2017.27 & 80.40 & 31.90 & 35.58 & 74.37 & 58.91 \\
\hline $\mathbf{5}$ & CG & 31.78 & 202.19 & 347.81 & 58.10 & 44.73 & 58.67 & 22.33 & 70.26 \\
\hline $\mathbf{6}$ & GN & 158.04 & 2143.75 & 2750.31 & 77.90 & 29.30 & 33.18 & 84.21 & 53.28 \\
\hline $\mathbf{7}$ & SF(\%) & 80.00 & 0.50 & 0.90 & 54.20 & 8.70 & 11.81 & 10.60 & 13.20 \\
\hline $\mathbf{8}$ & GL(mm) & 9.12 & 0.90 & 1.00 & 89.60 & 10.38 & 10.97 & 1.85 & 20.24 \\
\hline $\mathbf{9}$ & GW(mm) & 2.57 & 0.13 & 0.14 & 94.50 & 14.01 & 14.41 & 0.72 & 28.06 \\
\hline $\mathbf{1 0}$ & GR & 3.64 & 0.62 & 0.70 & 88.10 & 21.62 & 23.04 & 1.52 & 41.80 \\
\hline $\mathbf{1 1}$ & TGW(g) & 22.62 & 10.76 & 21.04 & 51.10 & 14.50 & 20.28 & 4.83 & 21.36 \\
\hline $\mathbf{1 2}$ & YP(g) & 18.66 & 34.43 & 61.77 & 55.70 & 31.44 & 42.12 & 9.02 & 48.35 \\
\hline
\end{tabular}

PT, Number of productive per plant; PL, Panicle length; PH, Plant height; FG, Number of filled grains per panicle; CG, Number of chaffy grains per panicle; GN, Total grains number per panicle; GL, Grain length(mm); GW, Grain width(mm); GL/GW, Grain length to width ratio; TGW,1000-grain weight; YP, Yield per plant 
Higher phenotypic variation (PCV) was observed for productive tillers $(36.50 \%)$, plant height $(20.61 \%)$, filled grains $(35.58 \%)$, chaffy grains $(58.67 \%)$, total grains $(33.18 \%)$, grain ratio (23.04), 1000-grain weight $(20.28 \%)$ and grain yield $(42.12 \%)$ where as panicle length $(10.98 \%)$, spikelet fertility per cent $(11.81 \%)$, grain length $(10.97 \%)$ and grain width $(14.41)$ showed medium phenotypic coefficient of variation (Table 4). Higher genotypic variation (GCV) was observed for productive tillers $(25.02 \%)$, filled grains $(31.90 \%)$, chaffy grains $(44.73 \%)$, total grains $(29.30 \%)$, grain ratio $(21.62 \%)$ and grain yield $(31.44 \%)$ while plant height $(19.61 \%)$, grain length $(10.38 \%)$, grain width (14.01\%) and 1000-grain weight $(14.50 \%)$ showed medium genotypic coefficient variation and plant length $(9.32 \%)$ and spikelet fertility per cent $(8.70 \%)$ showed low genotypic coefficient of variation (Table 4). High PCV on grain yield was also reported by Abebe et al., (2017) which is in agreement with this present study. In general, high coefficient of variability shows scope of selection in favour of traits of interest and low coefficient of variability indicates the need for creation of variability and selection.

Among the studied traits broad sense heritability ranged from $47.00 \%$ (productive tillers to $94.50 \%$ grain width). Panicle length $(72.20 \%)$, plant height $(90.60 \%)$, field grains $(80.40 \%)$, total grains $(77.90 \%)$, grain length $(89.60 \%)$, grain width $(94.50 \%)$ and grain ratio $(88.10 \%)$ were observed highly heritable traits. Productive tillers $(47.00 \%)$ and chaffy grains $(58.10 \%)$, spikelet fertility per cent $(54.20 \%)$, 1000 -grain weight $(51.10 \%)$ and grain yield $(55.70 \%)$ showed moderately heritable traits (Table 4). Similar report was reported by Gyawali et al., (2018) for grain yield. High to medium level heritability for grain yield was reported by Gyawali et al., (2018), Bandhi et al., (2018), Abebe et al., (2017) may be due to the influence of the environment on the yield as it is polygenic trait. Low heritability estimates might be due to the variation of environmental component involved for those traits and vice versa. High heritability estimated traits indicated a high response to selection for particular traits. Estimated heritability itself alone is not very much useful because it includes the effect of both additive and non additive gene. The genetic advance is therefore a useful indicator to achieve expected result on the trait of interest of a population after selection. Genetic advance in percentage of mean give more precise result in comparison to only genetic advance. In the present study moderate genetic advance as percent of mean was estimated for panicle length $(16.32 \%)$ and spikelet fertility per cent $(13.20 \%)$ and other traits showed high genetic advances $(>20 \%)$ in Table 4. This indicates most of observed characters among tested genotypes governed by additive gene action. The characters plant height, filled grains, total grains, grain length, grain width and grain ratio have high genetic advance as per cent of mean along with high heritability (Table 4). Similar reports were reported by (Dhurai et al., 2018 and Anjaneyulu et al., 2010) for plant height and total grains. High heritability with high genetic advance as per cent of mean indicates that these characters are largely controlled by additive gene action would be effective for selecting superior varieties.

In conclusion this study generally indicated that there were differences among the genotypes which revealed that there was genetic variation among the genotypes studied. In the present study, phenotypic coefficient of variation in general were higher than genotypic coefficient of variation for all the traits indicating high environmental effect on the expression of these traits except grain length (PCV 10.97\%, GCV $10.38 \%$ ) and grain width (PCV $14.41 \%$, GCV $14.01 \%$ ) which were less affected by environment for expression. Thus, selection based on phenotypic performance for grain length and grain width would be effective to bring about considerable genetic improvement. High heritability with high genetic advance as per cent of mean indicates that these characters are largely controlled by additive gene action would be effective for selecting superior varieties. 


\section{Conflicts of Interest}

The authors declare no conflicts of interest

\section{Acknowledgement}

We thankful to the Head, Scientists, Professors and technical staff, Department of Genetics and Plant Breeding, S.V. Agricultural College, Tirupati and RARS, Tirupati, for their valuable assistance.

\section{References}

Abebe, T., Alamerew, S., and Tulu, L. 2017. Genetic variability, heritability and genetic advance for yield and its related traits in rainfed lowland rice (Oryza sativa L.) genotypes at Fogera and Pawe, Ethiopia. Advances in Crop Science and Technology, 5, (272).

Adhikari, B. N., Joshi, B. P., Shrestha, J., and Bhatta, N. R. 2018. Genetic variability, heritability, genetic advance and correlation among yield and yield components of rice (Oryza sativa L.). Journal of Agriculture and Natural Resources, 1(1), 149-160.

Anjaneyulu,M., Reddy.D.R. and Reddy, K.H.P. 2010. Genetic variability, heritability and genetic advance in rice (Oryza sativa L.).Research on Crops, 11(2):415-416

Bandi, H.R.K., Satyanarayana, P.V., Babu, D.R., Chamundeswari, N., Rao, V.S., and Raju, S.K. 2018. Genetic variability estimates for yield and yield components traits and quality traits in rice (Oryza sativa L.). International Journal of Current Microbiology and Applied Sciences. 7(5), 551-559.

Dhurai, S.Y., Reddy, D.M., Bhati, P.K. and
Ravi, S. 2013. Studies on variability, heritability and genetic advance for yield and quality traits in rice (Oryza sativa L.). Progressive Research. 8(Special issue): 482-484.

Gyawali, S., Poudel, A., and Poudel, S. 2018. Genetic variability and association analysis in different rice genotypes in mid hill of western Nepal. Acta Scientific Agriculture, 2(9), 69-76.

Johnson, H.W, Robinson, J.F, and Comstock, R.E. 1955. Estimation of genetic and environmental variability in soya bean. Agronomy Journal 7: 314-318.

Lingaiah, N. 2015. Genetic variability, heritability and genetic advance in rice (Oryza sativa L.) Asian Journal of Environmental Sciences. 10(1):110-112.

Rashid, M.M., Nuruzzaman, M., Hassan, L., and Begum, S.N. 2017. Genetic variability analysis for various yield attributing traits in rice genotypes. Journal of the Bangladesh Agricultural University, 15(1), 15-19.

Shahriar, M.H, Robin, A.H.K. and Hoque. A. 2014. Diversity assessment of yield, yield contributing traits, and earliness of advanced T-aman rice (Oryza sativa L.) lines. Journal of Bioscience and Agriculture Research, 1(2):102-112.

Singh, A.K., Anju, S., Shama, P. and Singh, P.K. 2014. Studies on Genetic Characteristic of Upland Rice (Oryza sativa L.). International Journal of Agriculture, Environment and Biotechnology, 6:515-520.

Sivasubramanian,S. and Madhavamenon, P. 1973.Combining ability in rice. Madras Agricultural Journal. 60: 419-421

USDA. 2020. Foreign Agricultural Service. Global Market Analysis.

\section{How to cite this article:}

Ally Mwichande Russinga, A. Srividhya, V. L. N. Reddy and Latha, P. 2020. Studies on Variability, Heritability and Genetic Advance for Yield and its Related Traits in Rice (Oryza sativa L) Genotypes. Int.J.Curr.Microbiol.App.Sci. 9(09): 3180-3186. doi: https://doi.org/10.20546/ijcmas.2020.909.393 